\title{
A novel tetraarylpyrene host: Conformation-dependent inclusion of guest molecules in the crystal lattice
}

\author{
PALANI NATARAJAN ${ }^{1}$, PALOTH VENUGOPALAN ${ }^{2} *$ and \\ JARUGU NARASIMHA MOORTHY ${ }^{1, *}$ \\ ${ }^{1}$ Department of Chemistry, Indian Institute of Technology, Kanpur 208016 \\ ${ }^{2}$ Department of Chemistry, Panjab University, Chandigarh 160014 \\ e-mail: moorthy@iitk.ac.in; venugopalanp@yahoo.com
}

\begin{abstract}
Tetrakis(2,6-dimethyl-4-acetoxyphenyl)pyrene $\mathbf{H 2}$ containing flexible acetate functionalities at the para positions of sterically-hindered and rigid aryl rings functions as an inclusion host system. Depending on the orientations of the acetate functionalities, a variety of conformers may indeed be expected. A limited number of the crystal structures of the inclusions compounds of $\mathbf{H} 2$ reveal that one indeed observes 2 different conformations for the host based on the orientations of the acetate functionalities. The inclusion compound of $\mathbf{H 2}$ with benzene guest molecules is particularly appealing in terms of how the latter are held in trough domains of the host by weak $\mathrm{C}-\mathrm{H} \cdots \mathrm{O}$ and $\mathrm{C}-\mathrm{H} \cdots \pi$ hydrogen bonds. More experimentation and analyses of crystal structures of such systems is expected to lead to better insights toward realizing multicomponent molecular crystals in a rational manner.
\end{abstract}

Keywords. Inclusion compounds; X-ray diffraction; conformational analysis; self-assembly; supramolecular chemistry.

\section{Introduction}

The investigation of solid state host-guest molecular aggregates that represent a paradigm for multicomponent molecular assemblies is important, and paves way for understanding the link between chemistry and biology. ${ }^{1-5}$ The host-guest inclusion chemistry is relevant in diverse applications that range from optical resolution through polymerization in matrices to the protection and stabilization of hazardous chemicals and sensitive pharmaceuticals, respectively. ${ }^{6-11}$ Thus, there is an emphasis of interest in new and novel inclusion host systems discovered either by serendipity or by rational design. ${ }^{2}$ The latter constitutes an endearing goal, which entails the design at a molecular level taking into consideration of topological attributes of the overall skeleton and the intermolecular interactions that the molecular systems may lend themselves to. ${ }^{12-15}$

There has been considerable interest in the creation of molecular receptors that selectively bind neutral organic molecules, as they constitute models for substrate-receptor biochemistry. ${ }^{1-5}$ In our laboratories, we recently designed sterically-hindered 1,3,6,8-tetrakis(2,6-dimethyl-4-methoxyphenyl) py-

*For correspondence rene $\mathrm{H1}$ with $D_{2 \mathrm{~h}}$-symmetry as a host system with three distinct domains, viz. trough, basin and concave (chart 1), for guest inclusion. ${ }^{16,17}$ In a comprehensive investigation, we have shown that diverse guest molecules are included by the host $\mathbf{H 1}$ in solid state in all the three domains. Indeed, the crystal structure analysis of a large number of inclusion compounds permitted the recognition of selective binding of larger aromatics in trough regions and aliphatic guests in concave regions. Based on this differential binding of guests in two distinct domains of the host $\mathbf{H 1}$, we demonstrated a rational approach to the creation of ternary inclusion compounds with two dissimilar guests. ${ }^{17}$ In a logical extension of these studies, we sought to explore the inclusion chemistry of tetraacetyl analog $\mathbf{H} 2$ of host H1 (chart 1). The motivations for our interest in $\mathbf{H 2}$ are the following:

- The host $\mathbf{H 2}$ represents a homolog with an additional $\mathrm{C}=\mathrm{O}$ group that may effectively serve as a hydrogen bond acceptor for the included guests.

- The acetoxy group may enhance the guest binding owing to its flexibility, which might allow adoption of conformations that enable better binding of the guests. 




Chart 1. Structures of $\mathbf{H 1}$ and $\mathbf{H 2}$ and cartoon drawing that exemplifies the structures of hosts $\mathbf{H 1}$ and H2 with locations for guest binding.<smiles>Brc1cc(Br)c2ccc3c(Br)cc(Br)c4ccc1c2c43</smiles>
$\mathrm{Ar}-\mathrm{B}(\mathrm{OH})_{2}, \mathrm{Pd}\left(\mathrm{PPh}_{3}\right)_{4}$ $\mathrm{NaOH}$, dioxane, $90^{\circ} \mathrm{C}, 12 \mathrm{~h}$ $(82 \%)$<smiles>COc1cc(OC(C)=O)cc([N+](=O)[O-])c1</smiles>

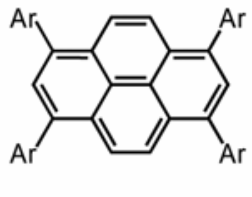
$\frac{\left(\mathrm{CH}_{3} \mathrm{CO}\right)_{2} \mathrm{O}}{\text { Cat. } \mathrm{H}_{2} \mathrm{SO}_{4}}$ $(92 \%)$<smiles>[Y]c1cc([Al])c2ccc3c([Al])cc([Al])c4ccc1c2c43</smiles><smiles></smiles><smiles>COc1cc(OC)cc([N+](=O)[O-])c1</smiles>

H1

Scheme 1. The synthetic route for the preparation of host $\mathbf{H 2}$.

- Depending on the orientations of the acetoxy groups in the crystal lattice, one may envisage conformation-dependent guest binding as well as conformational polymorphism. ${ }^{18}$

Here, we report that 1,3,6,8-tetrakis(2,6-dimethyl-4acetoxyaryl)pyrene $\mathbf{H} \mathbf{2}$ does indeed function as a unique host system. The limited investigations of guest inclusion reveal that $\mathbf{H} \mathbf{2}$ behaves as a responsive host system in that it appears to bind different guest molecules by exploiting the conformational flexibility inherent to four acetoxy groups. In other words, the host $\mathbf{H 2}$ lends itself to what may be termed conformation-dependent guest binding.

\section{Experimental}

Anhydrous tetrahydrofuran (THF) was freshly distilled over sodium prior to use. All other solvents were distilled prior to use. The progress of reactions was monitored by analytical thin layer chromatogra- phy (TLC) using aluminum sheets pre-coated with silica gel. Column chromatography was conducted with silica gel (60-120 $\mu \mathrm{m}$ mesh). ${ }^{1} \mathrm{H}$ NMR spectra were recorded on a $500 \mathrm{MHz}$ spectrometer using deuterated solvents. TGA measurements were carried out at a heating rate of $10^{\circ} \mathrm{C} / \mathrm{min}$ under nitrogen gas atmosphere. Commercial chemicals were used as received.

\subsection{Synthesis of 1,3,6,8-tetrakis(2,6-dimethyl-4- acetoxyphenyl)pyrene $\mathbf{H 2}$}

The synthesis of 1,3,6,8-tetrakis(2,6-dimethyl-4methoxyphenyl)pyrene $\mathbf{H 1}$ from 4-fold Suzuki coupling of 1,3,6,8-tetrabromopyrene with 2,6dimethyl-4-methoxyphenylboronic acid using $\operatorname{Pd}\left(\mathrm{PPh}_{3}\right)_{4}$ as a catalyst has been previously reported by us. ${ }^{19}$ To a solution of $\mathbf{H 1}(1.0 \mathrm{~g}, 1.36 \mathrm{mmol})$ in $30 \mathrm{~mL}$ of dry $\mathrm{CH}_{2} \mathrm{Cl}_{2}$ at $0^{\circ} \mathrm{C}$ was added $\mathrm{BBr}_{3}$ $(0.6 \mathrm{~mL}, 5.42 \mathrm{mmol})$ drop-wise under a $\mathrm{N}_{2}$ gas atmosphere. The reaction mixture was allowed to stir 
overnight. Subsequently, it was quenched with $10 \%$ $\mathrm{HCl}$ (ca. $10 \mathrm{~mL}$ ), extracted with ethyl acetate, dried over $\mathrm{Na}_{2} \mathrm{SO}_{4}$, treated with charcoal, filtered and concentrated. Filtration over a short-pad of silica gel using a mixture of ethyl acetate and pet. ether $(50: 50)$ led to 1,3,6,8-tetrakis(2,6-dimethyl-4hydroxyphenyl)pyrene (scheme 1) as a pure colourless solid in a quantitative yield $(>95 \%)$; IR $(\mathrm{KBr})$ $\mathrm{cm}^{-1}$ 2920, 3394(b); ${ }^{1} \mathrm{H}$ NMR (500 MHz, DMSO- $d_{6}$ ) $\delta 1.77(s, 24 \mathrm{H}), 6.61(s, 8 \mathrm{H}), 7.40(s, 2 \mathrm{H}), 7.43(s$, $4 \mathrm{H}), 9.27(s, 4 \mathrm{H}) ;{ }^{13} \mathrm{C}$ NMR $\left(125 \mathrm{MHz}\right.$, DMSO- $\left.d_{6}\right) \delta$ $21 \cdot 1,114 \cdot 8,124 \cdot 9,126 \cdot 8,128 \cdot 6,128 \cdot 8,130 \cdot 6$, 136.6, 137.8, 151.0. Anal. Calcd. For $\mathrm{C}_{48} \mathrm{H}_{42} \mathrm{O}_{4}$ : C 84.43, H 6.20. Found: C 84.42, H 6.18.

To a mixture of 1,3,6,8-tetrakis(2,6-dimethyl-4hydroxyphenyl)pyrene $(0.75 \mathrm{~g}, 1.1 \mathrm{mmol})$ and acetic anhydride $(0.9 \mathrm{~mL}, 8.8 \mathrm{mmol})$ was added a few drops of concentrated $\mathrm{H}_{2} \mathrm{SO}_{4}$. The reaction mixture was stirred for $12 \mathrm{~h}$ at $60^{\circ} \mathrm{C}$ and cooled to room temperature, and then poured into $50 \mathrm{~mL}$ of ice-cold water. The organic matter was extracted with diethyl ether. The combined extracts were washed with water and dried over $\mathrm{Na}_{2} \mathrm{SO}_{4}$. The solvent was removed in vacuum and the residual viscous solid was chromatographed on silica gel to afford $0.86 \mathrm{~g}(92 \%)$ of 1,3,6,8-tetrakis(2,6-dimethyl-4-acetoxyphenyl) pyrene $\mathbf{H 2}$ as a colourless solid, IR $(\mathrm{KBr}) \mathrm{cm}^{-1}$ 3042, 1592, 1179; ${ }^{1} \mathrm{H}$ NMR $\left(500 \mathrm{MHz}, \mathrm{CDCl}_{3}\right) \delta$ $1.90(s, 24 \mathrm{H}), 2.27(s, 12 \mathrm{H}), 6.87(s, 8 \mathrm{H}), 7.51(s$, $4 \mathrm{H}), 7.55(s, 2 \mathrm{H}) ;{ }^{13} \mathrm{C}$ NMR $\left(125 \mathrm{MHz}, \mathrm{CDCl}_{3}\right) \delta$ $20 \cdot 7,21 \cdot 2,120 \cdot 2,125 \cdot 0,125 \cdot 9,128 \cdot 6,128 \cdot 9,135 \cdot 7$, 137.4, 138.5, 149.9, 169.5. Anal. Calcd. For $\mathrm{C}_{56} \mathrm{H}_{50} \mathrm{O}_{8}$ : C 79.04, H 5.92. Found: C 78.99, H 5.91.

\subsection{Preparation of inclusion compounds}

The inclusion compounds of $\mathbf{H 2}$ with benzene $(\mathbf{H} 2 \bullet \mathbf{B Z})$ and chloroform $(\mathbf{H} 2 \bullet \mathbf{C H})$ were prepared by dissolving host $\mathbf{H 2}(20.0 \mathrm{mg})$ in $5 \mathrm{~mL}$ of respective solvents, i.e. benzene and chloroform, that were found to occupy lattice voids and evaporating the resultant solutions over a period of 7-10 days to yield colourless crystals quantitatively. The crystals were characterized by ${ }^{1} \mathrm{H}$ NMR and X-ray crystallography. The crystals of the compound with naphthalene and dimethoxyethane (H2•NAP) were obtained as follows: $30 \mathrm{mg}$ of $\mathbf{H 2}$ with 4 equivalents of naphthalene were dissolved in $4 \mathrm{~mL}$ of $1,2-$ dimethoxyethane (DME), and the resultant homogeneous solution was slowly evaporated over a period of 10 days at room temperature.

\section{$2.3 X$-ray crystal structure determination}

A good quality crystal in each case was mounted over a glass fibre, cooled to $100 \mathrm{~K}$, and the intensity data were collected on a Bruker Nonius SMART APEX CCD detector system with Mo-sealed Siemens ceramic diffraction tube $(\lambda=0.71073 \AA)$ and a highly oriented graphite monochromator operating at $50 \mathrm{kV}$ and $30 \mathrm{~mA}$. The data were collected on a hemisphere mode and processed with Bruker SAINTPLUS. Empirical absorption correction was made using Bruker SADABS. The structure was solved in each case by Direct Methods using SHELXTL package and refined by full matrix leastsquares method based on $F^{2}$ using SHELX-97 program. ${ }^{20}$ All the non-hydrogen atoms were refined anisotropically. The hydrogen atoms were included in the ideal positions with fixed isotropic $U$ values and were riding with their respective non-hydrogen atoms. The experimental details of crystal data, intensity measurements, structure solution and refinements are presented in table 1. CCDC-773342 $(\mathbf{H} 2 \bullet \mathbf{B Z})$, CCDC-773343 (H2•CH) and CCDC773344 (H2-NAP) contain the supplementary crystallographic data for this paper. Copies of these data can be obtained free of charge from the Cambridge Crystallographic Data Centre (www.ccdc.cam.ac.uk/ data_request/cif).

\section{Results and discussion}

The host $\mathbf{H 2}$ was conveniently synthesized by demethylation of compound $\mathbf{H} 1$ using $\mathrm{BBr}_{3}$ followed by treatment of the resulting tetraphenol with acetic anhydride, scheme 1. The synthesis of host $\mathbf{H 1}$ has already been reported by us in the context of organic light emitting diodes (OLEDs). ${ }^{19}$ Crystallization of host $\mathbf{H 2}$ was carried out from a variety of solvents and also with various combinations of solvents. The crystals were readily obtained from benzene, $\mathrm{CHCl}_{3}$ and a mixture of naphthalene and 1,2dimethoxyethane (DME). The X-ray crystal structure analysis in conjunction with ${ }^{1} \mathrm{H}$ NMR analysis of the crystals revealed the presence of guest inclusion. In table 1 are summarized the details of crystal data, host:guest stoichiometry and guest accessible volume, as calculated by the program PLATON.

\subsection{The inclusion compound with benzene, $\mathbf{H 2} \cdot \mathbf{~ B Z}$}

The crystals of $\mathbf{H} \mathbf{2} \bullet$ benzene were found to belong to the monoclinic crystal system with space group 
Table 1. The crystal data, host:guest stoichiometry and guest accessible volume for the inclusion compounds of $\mathbf{H 2}$.

\begin{tabular}{|c|c|c|c|}
\hline Identification code & H2•BZ & $\mathrm{H} 2 \bullet \mathbf{C H}$ & H2•NAP \\
\hline Empirical formula & $\mathrm{C}_{74} \mathrm{H}_{68} \mathrm{O}_{8}$ & $\mathrm{C}_{60} \mathrm{H}_{54} \mathrm{Cl}_{12} \mathrm{O}_{8}$ & $\mathrm{C}_{70} \mathrm{H}_{68} \mathrm{O}_{10}$ \\
\hline Formula weight & $1085 \cdot 28$ & $1328 \cdot 43$ & $1069 \cdot 24$ \\
\hline Temperature (K) & $100(2)$ & $100(2)$ & $100(2)$ \\
\hline Wavelength $(\AA)$ & 0.71073 & 0.71073 & 0.71073 \\
\hline Crystal system & Monoclinic & Monoclinic & Monoclinic \\
\hline Space group & $P 2_{1} / n($ no. 14$)$ & $P 2_{1} / c($ no. 14$)$ & $C 2 / c($ no. 15$)$ \\
\hline$a(\AA)$ & $12 \cdot 831(2)$ & $15 \cdot 063(5)$ & $15 \cdot 070(7)$ \\
\hline$b(\AA)$ & $8 \cdot 112(8)$ & $20 \cdot 041(7)$ & $18 \cdot 528(7)$ \\
\hline$c(\AA)$ & $30 \cdot 865(6)$ & $10 \cdot 590(4)$ & $21 \cdot 117(8)$ \\
\hline$\alpha(\mathrm{deg})$ & $90 \cdot 00$ & $90 \cdot 00$ & $90 \cdot 00$ \\
\hline$\beta($ deg $)$ & $99 \cdot 35(3)$ & $92 \cdot 96(3)$ & $108 \cdot 33(3)$ \\
\hline$\gamma(\mathrm{deg})$ & $90 \cdot 00$ & $90 \cdot 00$ & $90 \cdot 00$ \\
\hline Volume $\left(\AA^{3}\right)$ & $3169 \cdot 5(1)$ & $3193 \cdot 0(2)$ & $5597 \cdot 0(4)$ \\
\hline$Z$ & 2 & 2 & 4 \\
\hline Calculated density $\left(\mathrm{mg} / \mathrm{m}^{3}\right)$ & $1 \cdot 137$ & $1 \cdot 382$ & $1 \cdot 269$ \\
\hline Absorption coefficient $\left(\mathrm{mm}^{-1}\right)$ & 0.073 & 0.571 & 0.084 \\
\hline$F(000)$ & 1152 & 1364 & 2272 \\
\hline Theta range (deg) & $2 \cdot 36$ to $25 \cdot 00$ & $2 \cdot 51$ to 25.00 & $2 \cdot 28$ to $25 \cdot 00$ \\
\hline Scan type & $2 \theta-\theta$ & $2 \theta-\theta$ & $2 \theta-\theta$ \\
\hline Reflections collected & 15687 & 15944 & 14103 \\
\hline Independent reflections & $5524[R(\mathrm{int})=0.0370]$ & $5558[R($ int $)=0.0757]$ & $4838[R($ int $)=0.0604]$ \\
\hline \multirow[t]{2}{*}{ Refinement method } & Full-matrix & Full-matrix & Full-matrix \\
\hline & least-squares on $F^{2}$ & least-squares on $F^{2}$ & least-squares on $F^{2}$ \\
\hline Data/restraints/parameters & $5524 / 0 / 370$ & $5558 / 102 / 450$ & $4838 / 119 / 414$ \\
\hline Goodness-of-fit on $F^{2}$ & 1.051 & 1.046 & 1.086 \\
\hline Final $R$ indices $[I>2 \sigma(I)]$ & $\begin{array}{l}R_{1}=0.0644, \\
w R_{2}=0.1643\end{array}$ & $\begin{array}{l}R_{1}=0.0824, \\
w R_{2}=0.1814\end{array}$ & $\begin{array}{l}R_{1}=0.0937 \\
w R_{2}=0.2258\end{array}$ \\
\hline$R$ indices (all data) & $\begin{array}{l}R_{1}=0.1066 \\
w R_{2}=0.1850\end{array}$ & $\begin{array}{l}R_{1}=0.1746 \\
w R_{2}=0.2109\end{array}$ & $\begin{array}{l}R_{1}=0.1856 \\
w R_{2}=0.2671\end{array}$ \\
\hline Largest diff. peak and hole $\left(\mathrm{e} \AA^{-3}\right)$ & $0 \cdot 381$ and $-0 \cdot 211$ & 0.260 and -0.262 & 0.437 and -0.240 \\
\hline Host : Guest & $1: 3$ & $1: 4$ & $1: 1: 1$ \\
\hline$V(\%)$ & 35 & 36 & 46 \\
\hline
\end{tabular}

$P 2_{1} / n$. The asymmetric unit was found to contain only half of the host $\mathbf{H 2}$ (located on the crystallographic centers of inversion) with 1.5 benzene guest molecules. Thus, the host:guest stoichiometry is $1: 3$, which was also established by TGA analysis. The latter reveals that the occluded benzene molecules escape from the lattice at around $150^{\circ} \mathrm{C}$ and that the compound begins to decompose at $430^{\circ} \mathrm{C}$. The four 4-acetoxy-2,6-dimethylphenyl rings are found to be approximately orthogonal to the pyrene platform; the calculated angles between the planes for the aryl rings with the central pyrene ring are: $77.45^{\circ}$ and $88.56^{\circ}$. The host $\mathbf{H 2}$ is found to adopt the conformation 'in-in-in-in' (figure 1A).

In the lattice, the host $\mathbf{H 2}$ is found to form $\mathrm{C}-\mathrm{H} \cdots \mathrm{O}$ hydrogen bonded strands along the a-axis with concave regions of the translationally related molecules enclosing a square-shaped cavity down baxis, within which one benzene is trapped as a guest molecule (figure $2 \mathrm{c}$ ). The second guest molecule is held in the trough region of host via $\mathrm{C}-\mathrm{H} \cdots \mathrm{O}$ and $\mathrm{C}-\mathrm{H} \cdots \pi$ hydrogen bonds, as shown separately in figure 2a. Clearly, the guest molecules are accommodated in the two distinct domains of the host system. Two neighbouring strands along a-axis are displaced in a staggered manner to make up a corrugated layer along c-axis. The layer is stabilized via $\mathrm{C}-\mathrm{H} \cdots \pi$ hydrogen bonds between the central pyrene and $-\mathrm{CH}_{3}$ groups of $\mathrm{COCH}_{3}$ moiety. The entire hostguest assembly is stabilized by $\mathrm{C}-\mathrm{H} \cdots \mathrm{O}$ and $\mathrm{C}-\mathrm{H} \cdots \pi$ hydrogen bonds. ${ }^{21,22}$ Details of intermolecular interactions are listed in table 2. As revealed by PLATON, approximately $35 \%$ of the volume is occupied by the included guest molecules.

\subsection{The inclusion compound with chloroform, $\mathrm{H} 2 \cdot \mathbf{C H}$}

Crystallization of $\mathbf{H 2}$ in $\mathrm{CHCl}_{3}$ led to rectangular crystals in a quantitative yield. The crystals of 


\section{Centrosymmetric}
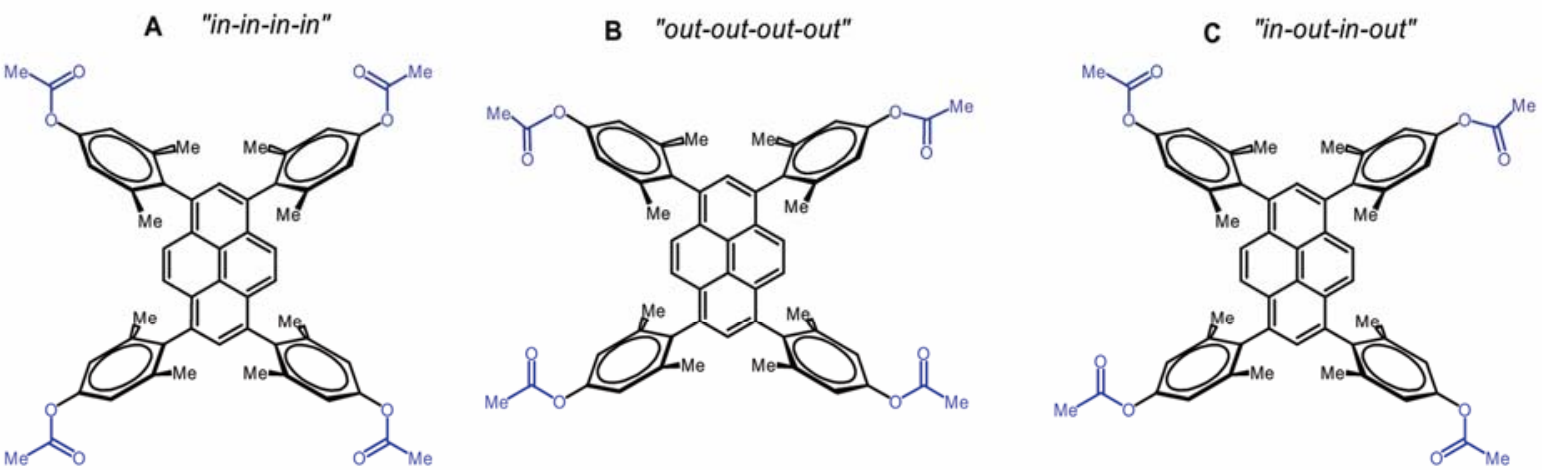

\section{mirror symmetric}


unsymmetrical


Figure 1. Various conformations possible for the acetoxy host $\mathbf{H 2}$.

$\mathbf{H 2} \cdot \mathbf{C H}$ were found to belong to the monoclinic crystal system with the space group $P 2_{1} / c$. The asymmetric unit contains only half of the host skeleton with 2 guest $\mathrm{CHCl}_{3}$ molecules, which are disordered over two positions. The refinement for the latter was achieved by applying partial occupancies. The calculated angles between the planes for the orthogonally oriented dimethylaryl rings and the pyrene platform are: $70.54^{\circ}$ and $81.84^{\circ}$, which are ca. $10^{\circ}$ lesser than those observed for the crystals of H2•BZ. The conformation adopted by the host is in-out-in-out (figure 1C).
In the crystal lattice, the host $\mathbf{H} \mathbf{2}$ forms 2D layers down c-axis with channels for guest accommodation. The porous assemblies are stabilized by weak $\mathrm{C}-\mathrm{H} \cdots \mathrm{O}$ hydrogen bonds between carbonyl oxygen and the hydrogens of methyl groups (figure $3 b$ ). The channels down the $c$-axis are relatively much bigger (approximate diagonal dimensions, $11.2 \times 10.2 \AA$ ) than the overall size of the chloroform guest molecules, and as a consequence a large number of solvent molecule (Host: Guest $=1: 4$ ) are accommodated in the lattice. Another noteworthy feature is that the channels of the host lack any functional groups that 
(a)

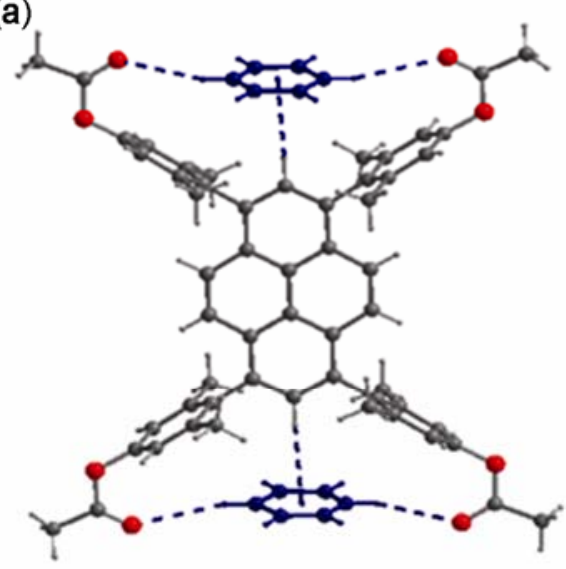

(b)

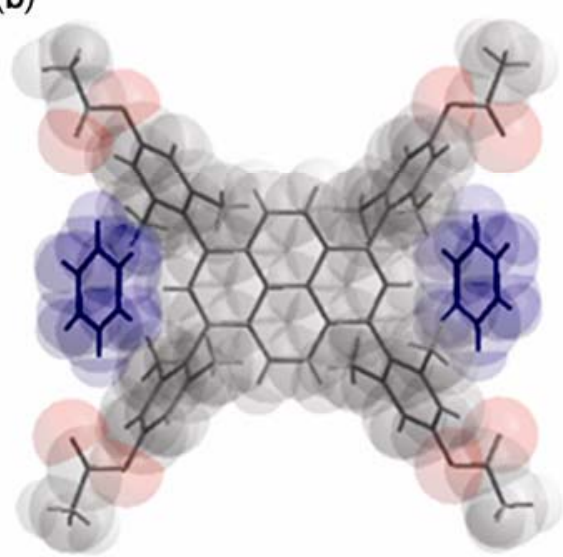

(c)

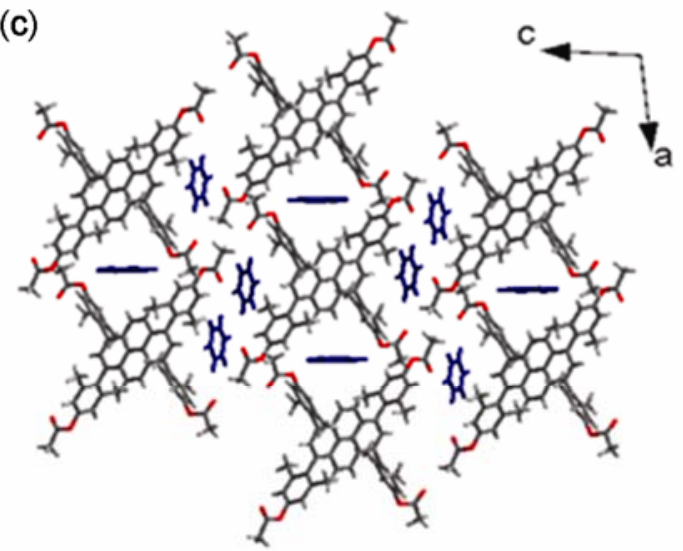

(d)

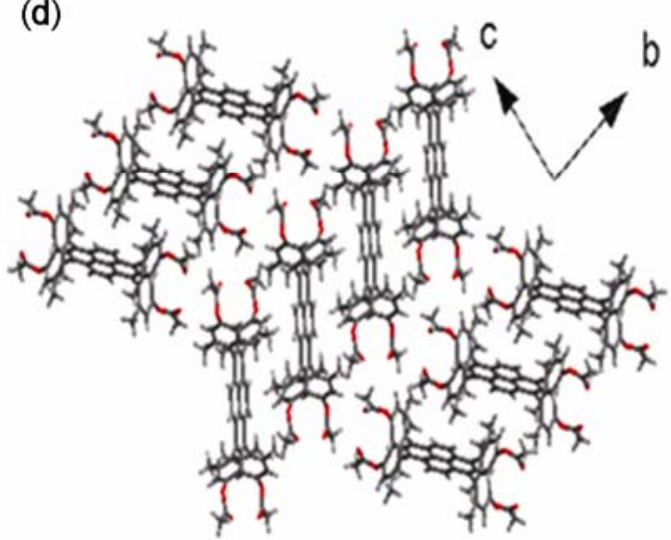

Figure 2. The molecular structure of $\mathbf{H} \mathbf{2}$ with guest benzene (a and $\mathbf{b}$ ), typical host-guest assembly of $\mathbf{H 2} \mathbf{B Z Z}$ in the crystal lattice down $b$-axis (c) and the arrangement of host $\mathbf{H 2}$ molecules down $a$-axis (d).

may bind the guest chloroform molecules strongly, which renders the guests to adopt multiple orientations that lead to disorder.

As shown in figure $3 \mathrm{c}$, two neighbouring porous layers are displaced in a staggered manner to make up the crystals. The layer displacement is stabilized via $\mathrm{C}-\mathrm{H} \cdots \pi$ hydrogen bonds between the central pyrene and $\mathrm{CH}_{3}$ groups of $\mathrm{COCH}_{3}$ moiety. The entire host-guest assembly is stabilized by $\mathrm{C}-\mathrm{H} \cdots \mathrm{O}$ and $\mathrm{C}-\mathrm{H} \cdots \pi$ hydrogen bonds and halogen-halogen interactions. Details of intermolecular interactions are listed in table 2 .

\subsection{The inclusion compound with naphthalene-DME, H2•NAP}

Crystallization of $\mathbf{H 2}$ in DME containing 4 equivalents of naphthalene led to block-shaped crystals. The crystals of H2•NAP were found to belong to monoclinic (space group $\mathrm{C} 2 / \mathrm{c}$ ) with four molecules of host $\mathbf{H 2}$, four naphthalene and four DME mole- cules in the unit cell. The calculated angles between the planes of the orthogonally oriented dimethylaryl rings and the central pyrene core are: $73.22^{\circ}$ and $82.12^{\circ}$, which are ca. $7^{\circ}$ lesser than those observed in the crystals of $\mathbf{H} \mathbf{2} \bullet \mathbf{B Z}$. The conformation adopted by the host is in-out-in-out (figure 1C), which is similar to the one found for $\mathbf{H} 2 \bullet \mathbf{C H}$.

The crystal packing of $\mathbf{H 2} \cdot \mathbf{N A P}$ with guest molecules down $c$-axis is shown in figure $4 \mathrm{c}$. The $\mathrm{C}-\mathrm{H} \cdots \mathrm{O}$ hydrogen bonding between the dimethylaryl rings of the translationally-related molecules along the $b$-axis leads to voids in which the guests are entrapped. Each of the host molecules is found to involve in four $\mathrm{C}-\mathrm{H} \cdots \mathrm{O}$ hydrogen bonds with the neighbouring host molecules. Methyl groups of the $\mathrm{COCH}_{3}$ are found to involve in $\mathrm{C}-\mathrm{H} \cdots \pi$ hydrogen bonds with those of the neighbouring glide-related host molecules, such that one obtains a honeycomb structure with voids for guest inclusion (figure 4c). A careful inspection of the molecular association shows that one of the dimethylaryl rings of the 
Table 2. Weak intermolecular hydrogen bonds observed in the inclusion compounds of host $\mathbf{H 2}$ with different guest molecules.

\begin{tabular}{|c|c|c|c|}
\hline Interaction & $d / \AA$ & $\theta / \operatorname{deg}$ & Range of $\mathrm{C}-\mathrm{H} \cdots \pi \mathrm{d} / \AA$ \\
\hline \multicolumn{4}{|l|}{ H2•BZ } \\
\hline $\mathrm{C}_{28}-\mathrm{H} \cdots \mathrm{O}_{4}$ & $2 \cdot 918$ & $102 \cdot 21$ & \multirow{8}{*}{$2.84-2.97 \AA$} \\
\hline $\mathrm{C}_{18}-\mathrm{H} \cdots \mathrm{O}_{2}$ & $2 \cdot 762$ & $135 \cdot 39$ & \\
\hline $\mathrm{C}_{23}-\mathrm{H} \cdots \mathrm{O}_{3}$ & $2 \cdot 679$ & $164 \cdot 25$ & \\
\hline $\mathrm{C}_{13}-\mathrm{H} \cdots \mathrm{O}_{1}$ & $2 \cdot 656$ & $169 \cdot 38$ & \\
\hline $\mathrm{C}_{18}-\mathrm{H} \cdots \mathrm{O}_{2}$ & $2 \cdot 548$ & $119 \cdot 61$ & \\
\hline $\mathrm{C}_{29}-\mathrm{H}_{(\mathrm{g})} \cdots \mathrm{O}_{4}$ & $2 \cdot 549$ & $144 \cdot 72$ & \\
\hline $\mathrm{C}_{30}-\mathrm{H}_{(\mathrm{g})} \cdots \mathrm{O}_{2}$ & $2 \cdot 874$ & $166 \cdot 68$ & \\
\hline $\mathrm{C}_{35}-\mathrm{H}_{(\mathrm{g})} \cdots \mathrm{O}_{1}$ & $2 \cdot 712$ & $143 \cdot 98$ & \\
\hline \multicolumn{4}{|l|}{$\mathbf{H} 2 \cdot \mathbf{C H}$} \\
\hline $\mathrm{C}_{25}-\mathrm{H} \cdots \mathrm{O}_{2}$ & $2 \cdot 864$ & $118 \cdot 59$ & \multirow{5}{*}{$2 \cdot 92-2.99 \AA$} \\
\hline $\mathrm{C}_{18}-\mathrm{H} \cdots \mathrm{O}_{1}$ & $2 \cdot 819$ & $155 \cdot 77$ & \\
\hline $\mathrm{C}_{28}-\mathrm{H} \cdots \mathrm{O}_{2}$ & $2 \cdot 650$ & $138 \cdot 74$ & \\
\hline $\mathrm{C}_{16}-\mathrm{H} \cdots \mathrm{O}_{2}$ & $2 \cdot 610$ & $156 \cdot 28$ & \\
\hline $\mathrm{C}_{18}-\mathrm{H} \cdots \mathrm{O}_{1}$ & $2 \cdot 536$ & $144 \cdot 63$ & \\
\hline \multicolumn{4}{|l|}{ H2•NAP } \\
\hline $\mathrm{C}_{21}-\mathrm{H} \cdots \mathrm{O}_{4}$ & $2 \cdot 796$ & $153 \cdot 41$ & \multirow{5}{*}{$2.91-2.99 \AA$} \\
\hline $\mathrm{C}_{18}-\mathrm{H} \cdots \mathrm{O}_{4}$ & $2 \cdot 754$ & $132 \cdot 17$ & \\
\hline $\mathrm{C}_{25}-\mathrm{H} \cdots \mathrm{O}_{4}$ & $2 \cdot 662$ & $162 \cdot 13$ & \\
\hline $\mathrm{C}_{16}-\mathrm{H} \cdots \mathrm{O}_{1}$ & $2 \cdot 636$ & $117 \cdot 24$ & \\
\hline $\mathrm{C}_{18}-\mathrm{H} \cdots \mathrm{O}_{2}$ & $2 \cdot 412$ & $149 \cdot 73$ & \\
\hline
\end{tabular}
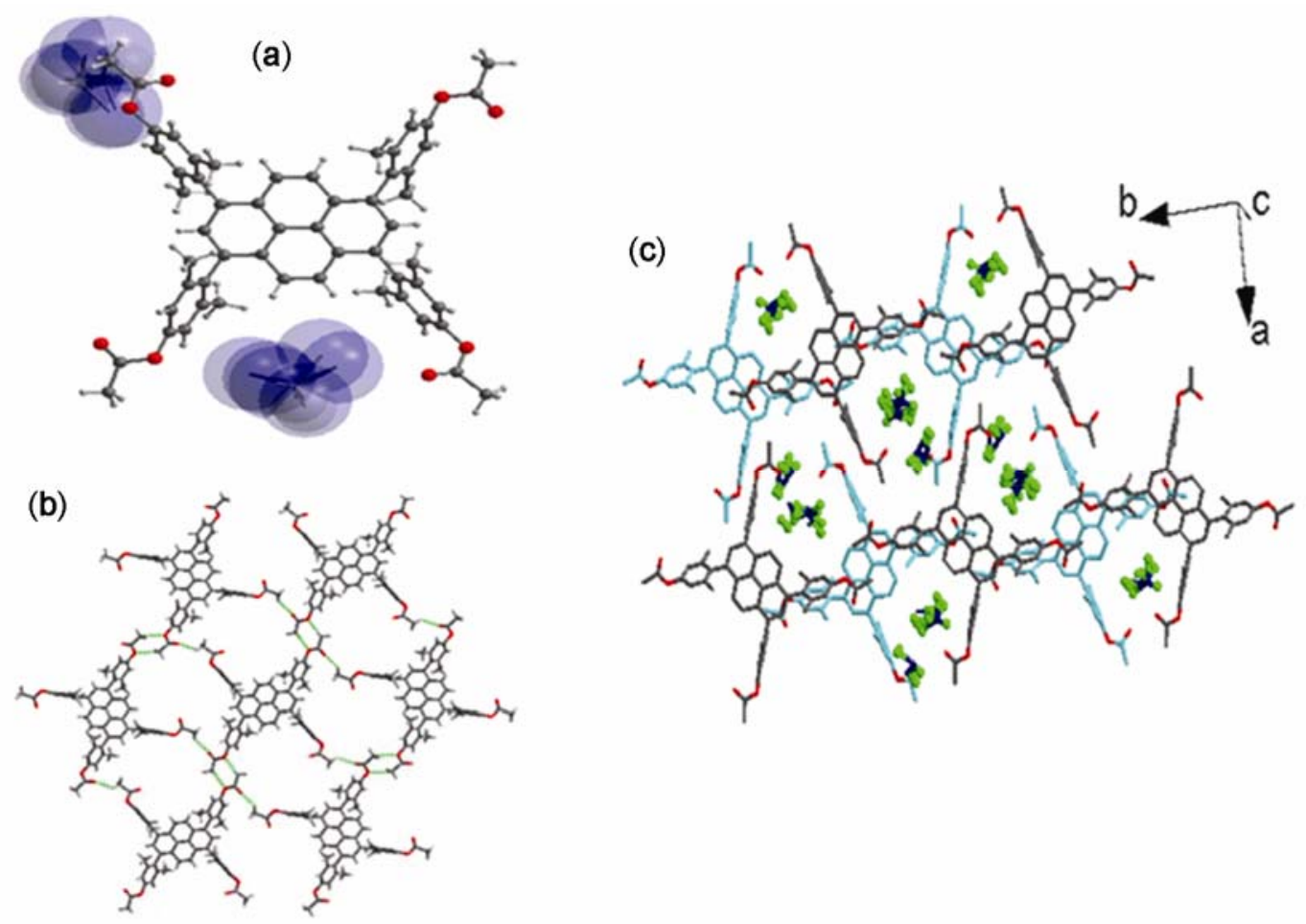

Figure 3. The molecular structure of $\mathbf{H 2}$ with guest $\mathrm{CHCl}_{3}$ (a), $2 \mathrm{D} \mathrm{C}-\mathrm{H} \cdots \mathrm{O}$ hydrogen bonded sheet arrangement of host $\mathbf{H 2}$ (b) and typical host-guest assembly of $\mathbf{H 2} \cdot \mathbf{C H}$ in the crystal lattice down c-axis (c). 

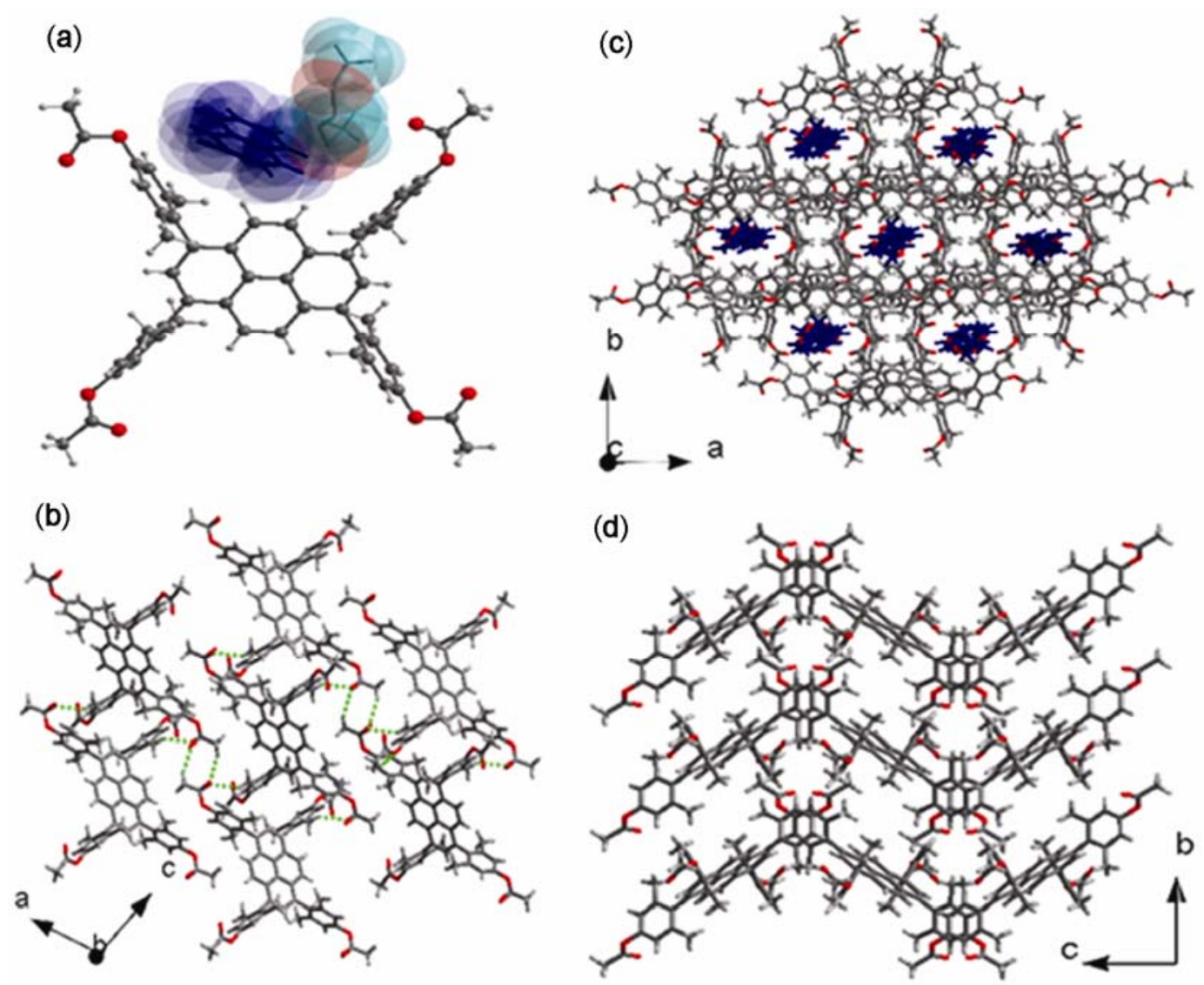

Figure 4. The molecular structure of $\mathbf{H 2}$ with guest naphthalene and DME (a) and the $\mathrm{C}-\mathrm{H}$... O hydrogen bond-mediated strands of host $\mathbf{H 2}$ along $b$-axis. Notice that the aryl rings of the host interject into the trough regions of the neighbouring molecules (b). The honeycomb kind of host-guest assembly down $c$-axis (c) and the arrangement of host $\mathbf{H 2}$ as corrugated sheets down $a$-axis (d).

adjacent molecules interjects into the trough of the neighbouring host molecule via two $\mathrm{C}-\mathrm{H} \cdots \mathrm{O}$ and two $\mathrm{C}-\mathrm{H} \cdots \pi$ hydrogen bonds that leads to columns down b-axis (figure 4b). As shown in Figure 4d, the molecules of $\mathbf{H} \mathbf{2}$ are arranged in corrugated sheets, and their packing is stabilized by stacking interactions between the dimethylaryl rings of adjacent molecules. The guest naphthalene forms $\mathrm{C}-\mathrm{H} \cdots \mathrm{O}$ and $\mathrm{C}-\mathrm{H} \cdots \pi$ interactions with host $\mathbf{H 2}$ in the lattice. Details of intermolecular interactions are listed in table 2.

First of all, our strategy that the molecules characterized by a flat aromatic base decked up with rigid aromatic panels can exhibit the phenomenon of guest inclusion is demonstrated by guest-binding inclusion behaviour of the host $\mathbf{H 2}{ }^{16,17}$ Because of the sterics, the dimethylaryl rings in $\mathbf{H} \mathbf{2}$ are expected to be orthogonal and rigid. Thus, the acetoxy groups on the rigid aryl rings were meant as handles to abet the binding of guests in concave/trough domains of the host via additional $\mathrm{C}-\mathrm{H} \cdots \mathrm{O} / \mathrm{C}-\mathrm{H} \cdots \pi$ hydrogen bonds. ${ }^{21,22}$ Introduction of such flexible groups may lead to as many as 7 conformational isomers shown in figure 1. Accordingly, based on the orientations of the acetoxy groups inward/outward of the trough, the conformational isomers are denoted by descriptions such as in-in-in-in, in-out-in-out, in-out-out-in, etc. Such a conformational flexibility is a priori expected to lend considerable liberty to the host systems to adopt geometries complimentary to varying sizes and shapes of guest molecules to allow excellent guest inclusion behaviour. A cursory glance at the various conformers in figure 1 shows that the geometries $\mathrm{A}-\mathrm{C}$ are centrosymmetric and $\mathrm{D}-\mathrm{E}$ are mirror symmetric, while $\mathrm{F}$ and $\mathrm{G}$ are unsymmetrical. Given the tendency of symmetric molecules to exploit crystallographic symmetry, one should expect guest inclusion with various conformational isomers leading to conformation-dependent guest inclusion. Viewed differently, the host may be said to explore conformational changes in response to the shape, size and electronic complementarity towards binding of the guest. 

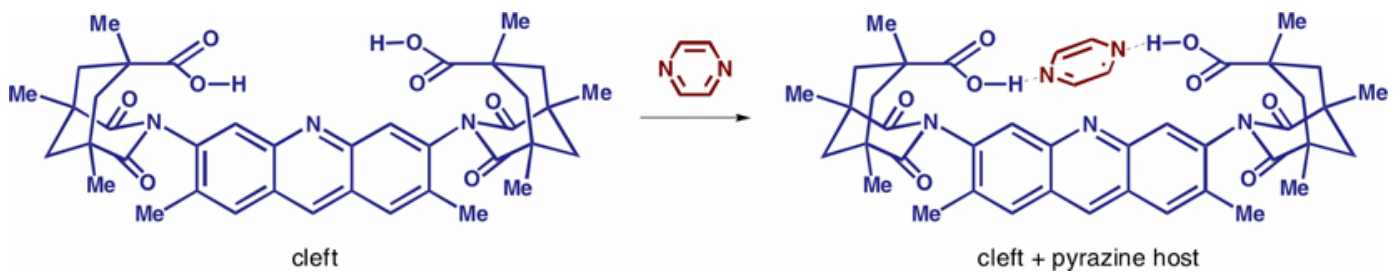

Figure 5. The structures of Rebek's diacid and its inclusion compound with the guest pyrazine (right).

The limited crystal structures of host $\mathbf{H} 2$ with benzene, naphthalene-DME and chloroform show that the host crystallizes with two different conformations. That is, the conformation adopted in the inclusion compounds of $\mathbf{H 2} \cdot \mathbf{B Z}$ is in-in-in-in (A, figure 1), while it is in-out-in-out (C, figure 1$)$ in H2•NAP and $\mathbf{H} 2 \bullet \mathbf{C H}$. Thus, the guest-dependent adoption of the conformation by $\mathbf{H 2}$ is clearly evident. ${ }^{23}$ The results may also be described as conformation-dependent guest inclusion. ${ }^{24}$ Of the three crystal structures of the inclusion compounds of $\mathbf{H 2}$ described, particularly appealing is the structure of that with benzene guest. The guest benzenes in $\mathbf{H} 2 \cdot \mathbf{B Z}$ are bound in 'trough' and 'concave' domains such that they are held by $\mathrm{C}-\mathrm{H} \cdots \mathrm{O}$ and $\mathrm{C}-\mathrm{H} \cdots \pi$ hydrogen bonds. The mode of binding of benzene reminisces molecular clefts, which have received much attention. ${ }^{25}$ In particular, the mode of benzene in 'trough' via weak hydrogen bonds is akin to Rebek's Kemp's triacid based imide that was demonstrated to bind pyrazine guest with $2 \mathrm{~N}-\mathrm{H} \cdots \mathrm{O}$ hydrogen bonds as shown in figure $5 .^{26,27}$

\section{Conclusions}

We have shown that tetraarylpyrene host $\mathbf{H 2}$ containing flexible acetate functionalities at the para positions of the sterically hindered and rigid aryl rings functions as an inclusion host system. A limited number of crystal structures of the inclusion compounds of $\mathbf{H} \mathbf{2}$ reveal that one observes 2 different conformations for the host based on the orientations of the acetate functionalities. The inclusion compound of $\mathbf{H 2}$ with benzene guest molecules is particularly appealing in terms how the guest is bound in the trough domains of the host by weak $\mathrm{C}-\mathrm{H} \cdots \mathrm{O}$ and $\mathrm{C}-\mathrm{H} \cdots \pi$ hydrogen bonds.

\section{Acknowledgements}

J N M is grateful to the Department of Science and Technology (DST), Government of India for generous financial support.

\section{References}

1. Atwood J L, Davies J E D and Macnicol D D 1984 In Inclusion compounds (London: Academic Press Inc)

2. Weber E 1987 and 1988 In Molecular inclusion and molecular recognition-Clathrates I and II topics in current chemistry (Berlin-Heidelberg: Springer-Verlag) vols 140 and 149

3. Desiraju G R 1989 Crystal engineering: The design of organic solids (Amsterdam, Netherlands: Elsevier)

4. Atwood J L, Davies J E D and Macnicol D D 1991 In Inclusion compounds (Oxford: Oxford University Press)

5. Atwood J L, Davies J E D, MacNicol D D, Vogtle F and Lehn J-M 1996 In Comprehensive supramolecular chemistry (Oxford: Pergamon)

6. Ramamurthy V 1991 Photochemistry in constrained and organized media (New York: VCH Publishers)

7. Desiraju G R 1997 Curr. Opin. Solid. State. Mater. Sci. 2451

8. Toda F and Bishop R 2004 Separation and reactions in organic supramolecular chemistry (New York: Wiley)

9. Miyata M 2004 Inclusion reactions and polymerization: Encyclopedia of supramolecular chemistry (New York: Marcel Decker) p. 705

10. Sozzani P, Bracco S, Comotti A, Ferretti L and Simonutti R 2005 Angew. Chem., Int. Ed. 441816

11. Vishweshwar P, McMahon J A, Bis J A and Zaworotko M J 2006 J. Pharm. Sci. 95499

12. Macnicol D D, Toda F and Bishop R 1996 Comprehensive supramolecular chemistry, solid state chemistry: Crystal engineering (Oxford: Pergamon Press)

13. Malek N, Maris T, Perron M-E and Wuest J D 2005 Angew. Chem., Int. Ed. 444021

14. Maly K E, Gagnon E, Maris T and Wuest J D 2007 J. Am. Chem. Soc. 1294306

15. Holman K T, Pivovar A M, Swift J A and Ward M D 2001 Acc. Chem. Res. 34107

16. Moorthy J N, Natarajan P and Venugopalan P 2009 J. Org. Chem. $\mathbf{7 4} 8566$

17. Moorthy J N, Natarajan P and Venugopalan P 2010 Chem. Commun. 463574

18. Nangia A 2008 Acc. Chem. Res. 41595

19. Moorthy J N, Natarajan P, Venkatakrishnan P, Huang D-F and Chow T J 2007 Org. Lett. 95215 
20. Sheldrick, G M 1997 SHELX-97 Program for the refinement and solution of crystal structures (University of Gottingen: Gottingen, Germany)

21. Desiraju G R and Steiner T 1999 The weak hydrogen bond in structural chemistry and biology (Oxford: Oxford University Press)

22. Nishio M 2005 Cryst. Eng. Commun. 6130
23. Miyata M, Tohnai N and Hisaki I 2007 Molecules 12 1973

24. Moorthy J N and Natarajan P 2008 J. Mol. Struct. 885139

25. Rebek J 1987 Science 2351478

26. Rebek J, Askew B, Islam N, Killoran M, Nemeth D and Wolak R $1985 \mathrm{~J}$. Am. Chem. Soc. 1076736

27. Pascal R A and Ho D M 1993 J. Am. Chem. Soc. 1158507 